\title{
Atividade enzimática do solo sob sistema de produção orgânica e convencional na cultura da cana-de-açúcar em Goiás
}

\section{Enzymatic activity of soil under organic and conventional management in the culture of sugar cane in Goiás}

\author{
Cristiano Ramos Evangelista ${ }^{1}$; Fábio Luiz Partelli²*; \\ Enderson Petrônio de Brito Ferreira ${ }^{3}$; Vládia Correchel ${ }^{4}$
}

\section{Resumo}

Objetivou-se avaliar a atividade das enzimas ligadas ao ciclo do carbono, à mineralização do fósforo e atividade enzimática total do solo cultivado com cana-de-açúcar orgânica certificada com e sem revolvimento do solo, orgânica em certificação, convencional com e sem queima da palhada e uma área remanescente de Cerrado no município de Goiatuba, GO, Brasil. Foi realizada coleta de solo em março (período chuvoso) e setembro (período de estiagem) de 2009, na profundidade de 0-10 $\mathrm{cm}$, para análises de matéria orgânica, $\mathrm{pH}, \mathrm{P}$, granulometria e atividade enzimática total, $\beta$-glicosidase e fosfatase ácida. Os dados foram submetidos às análises descritiva e multivariada. O sistema de produção orgânico certificado de cana-de-açúcar sem revolvimento do solo apresentou maiores níveis de atividade da $\beta$-glicosidase, indicando maior ciclagem da matéria orgânica em relação aos outros sistemas. Os maiores valores de fosfatase ácida foram observados nas coletas amostradas no período chuvoso na área remanescente de Cerrado, seguido pelo sistema de produção orgânico certificado sem revolvimento do solo. Menor atividade enzimática total foi observada no sistema que utiliza a queima da palhada antes da colheita. O solo remanescente de Cerrado seguido pelo sistema orgânico certificado de cana-de-açúcar sem revolvimento apresentaram os melhores indicadores de qualidade de solo.

Palavras-chave: $\beta$-glicosidase, atividade enzimática total, manejo orgânico, mineralização do carbono, fósforo orgânico, fosfatase ácida

\begin{abstract}
This work aimed to evaluate the activity of enzymes related with the carbon cycle, P mineralization and total enzymatic activity of soil cultivated with certified organic sugarcane with and without soil tillage, organic sugarcane under certification, conventional sugarcane with and without residue burning and a remaining area of Cerrado in Goiatuba, GO, Brazil. Soil samples were collected in March (summer) and in September (winter) 2009 from 0-10 cm depth for analysis of organic matter, $\mathrm{pH}, \mathrm{P}$, granulometry, total enzymatic activity, $\beta$-glucosidase and acid phosphatase. Data were subjected to descriptive and multivariate analyses. The certified organic management of sugarcane without soil tillage had higher levels of $\beta$-glucosidase activity, indicating increased cycling of organic matter in relation to other systems. The highest values of acid phosphatase were observed in the samples collected from the remaining area of Cerrado in the summer, followed by the certified organic management without soil
\end{abstract}

\footnotetext{
${ }^{1}$ Eng $^{\circ}$ Agr $^{\circ}$, Consultor do SEBRAE/GO, Goiânia, GO. E-mail: cristianoramosevangelista@yahoo.com.br

${ }^{2}$ D.Sc., Prof. da Universidade Federal do Espírito Santo, UFES, Centro Universitário Norte do Espírito Santo. Rod. BR 101 Norte, Km. 60, Bairro Litorâneo, 29932-540, São Mateus, ES. E-mail: partelli@yahoo.com.br

${ }^{3}$ D.Sc., Pesq. da Embrapa Arroz e Feijão, Santo Antônio de Goiás, GO. E-mail: enderson@cnpaf.embrapa.br

${ }^{4}$ D.Sc., Prof. da Universidade Federal de Goiás, UFG, Escola de Agronomia e Engenharia de Alimentos, Goiânia, GO. E-mail: vladiacorrechel@hotmail.com

* Autor para correspondência
} 
tillage. Lower total enzymatic activity was observed in the management involving residue burning before the crop harvest. The remaining soil of Cerrado, followed by the certified area with organic management of sugarcane without soil tillage presented the best indicators of soil quality.

Key words: $\beta$-glucosidase, FDA hydrolysis, organic management, carbon mineralization, organic phosphorus, acid phosphatase

\section{Introdução}

Os microrganismos são considerados as principais fontes de enzimas do solo. Portanto, o estudo da atividade enzimática tem sido reportado como indicador efetivo da qualidade do solo, da decomposição da matéria orgânica e da disponibilidade de nutrientes decorrentes das práticas de manejo ou do ambiente (QUILCHANO; MARANÓN, 2002). As enzimas de interesse na ciclagem de nutrientes são aquelas que catalisam a hidrólise de constituintes da matéria orgânica do solo (JOSHI; SHARMA; MISHRA, 1993; FIORETTO et al., 2001).

A cultura da cana-de-açúcar (Saccharum officinarum L.) movimenta um grande ramo da atividade agrícola do país. Como alimento, por meio do açúcar a cultura é a matéria prima que compõe a fabricação de inúmeros produtos industrializados que atendem as necessidades humanas. Referente à energia, a cana-de-açúcar apresenta grande potencial na produção de álcool combustível, atendendo às principais demandas de locomoção da população brasileira e mundial em substituição de parte dos combustíveis fósseis (CONAB, 2011). Também é possível gerar energia elétrica para consumo e venda, por meio da utilização do bagaço e palhiço (RIPOLI; RIPOLI, 2008).

Durante décadas, a cultura da cana-de-açúcar teve sua imagem como causadora de grandes impactos no ambiente. Atualmente, com emprego de novas tecnologias no campo de produção como irrigação com vinhaça tem melhorado as características químicas do solo (CARNEIRO et al., 2004a). Além disso, a colheita mecanizada, a adubação verde e orgânica, a rotação de cultura, o controle biológico eficiente e a utilização do sistema de plantio direto são algumas das práticas que têm facilitado a adoção de técnicas agroecológicas nas áreas de cultivo, avançando assim a uma etapa de produção orgânica.(SOARES et al., 2008). O sistema de plantio de direto de cana-de-açúcar além de proporcionar redução na utilização de herbicidas, proporcionou a redução da infestação de plantas espontâneas na cultura em 525\% segundo Duarte Júnior, Coelho e Freitas (2009). Essas eventuais mudanças proporcionadas pelo manejo podem ser quantificadas pela avaliação da qualidade do solo por meio de aspectos bioquímicos como a atividade enzimática. Segundo Paula et al. (2006) e Partelli (2008), o manejo orgânico na cultura do café por meio da adição de adubos orgânicos favorece os níveis de atividade enzimática no solo.

Em trabalho realizado por Silveira (2007), foram utilizadas a atividade enzimática de $\beta$-glicosidase, uréase, fosfatase ácida e atividade enzimática total (AET) como indicador das alterações do solo. Nesse trabalho, os autores observaram que a atividade enzimática foi influenciada pela quantidade de carbono orgânico no solo proveniente do plantio direto ou por deposição da mata. Os autores concluem que o carbono orgânico além de ser aproveitado como fonte de energia pelos microrganismos, protege as enzimas do ataque de enzimas proteolíticas, permanecendo de forma constante no solo. Segundo Deng e Tabatabai (1997), essa proteção se da pela formação de complexos enzimas-compostos húmicos, impossibilitando o acesso das enzimas proteolíticas as enzimas, principalmente a enzima $\beta$-glicosidase.

Em trabalho semelhante, Matsuoka (2006), concluiu que as enzimas $\beta$-glucosidase, fosfatase ácida, uréase e amidase são sensíveis à mudança do manejo da cultura podendo indicar alterações no solo. Dessa forma, estudos sobre a atividade 
das enzimas são bons indicativos de qualidade e sustentabilidade do solo cultivado. Contudo, informações sobre estes indicadores em diferentes sistemas de cultivo de cana-de-açúcar em solos de Cerrado são escassos.

Assim, objetivou-se avaliar a atividade das enzimas ligadas ao ciclo do carbono, à mineralização do fósforo e AET do solo cultivado com cana-deaçúcar sob agroecossistemas de produção orgânica certificada (com e sem revolvimento do solo), orgânica em certificação, convencional (com e sem queima da palha) e em área com remanescente de Cerrado.

\section{Material e Métodos}

Os trabalhos foram realizados em sistemas de produção comercial de cana-de-açúcar pertencentes à Usina Goiasa, no município de Goiatuba, Estado de Goiás, Brasil, localizada à 18 04' 29" W e 49 41' 44" S. Foram avaliados dois sistemas de produção orgânico (com e sem revolvimento do solo), um sistema de produção orgânico em processo de certificação, dois sistemas de produção convencional diferindo-os pela forma de colheita, (um com queima da palha e outro sem queima) e uma área de remanescente de Cerrado. O clima dessa região é tropical semi-úmido, apresentando duas estações climáticas bem definidas como apresentado na (Figura 1).

Figura 1. Valores médios das temperaturas máxima, média e mínima da atmosfera local e precipitação total registrada na estação meteorológica 101, Usina Goiasa, Goiatuba, GO, Brasil, no período de outubro de 2008 a setembro de 2009.

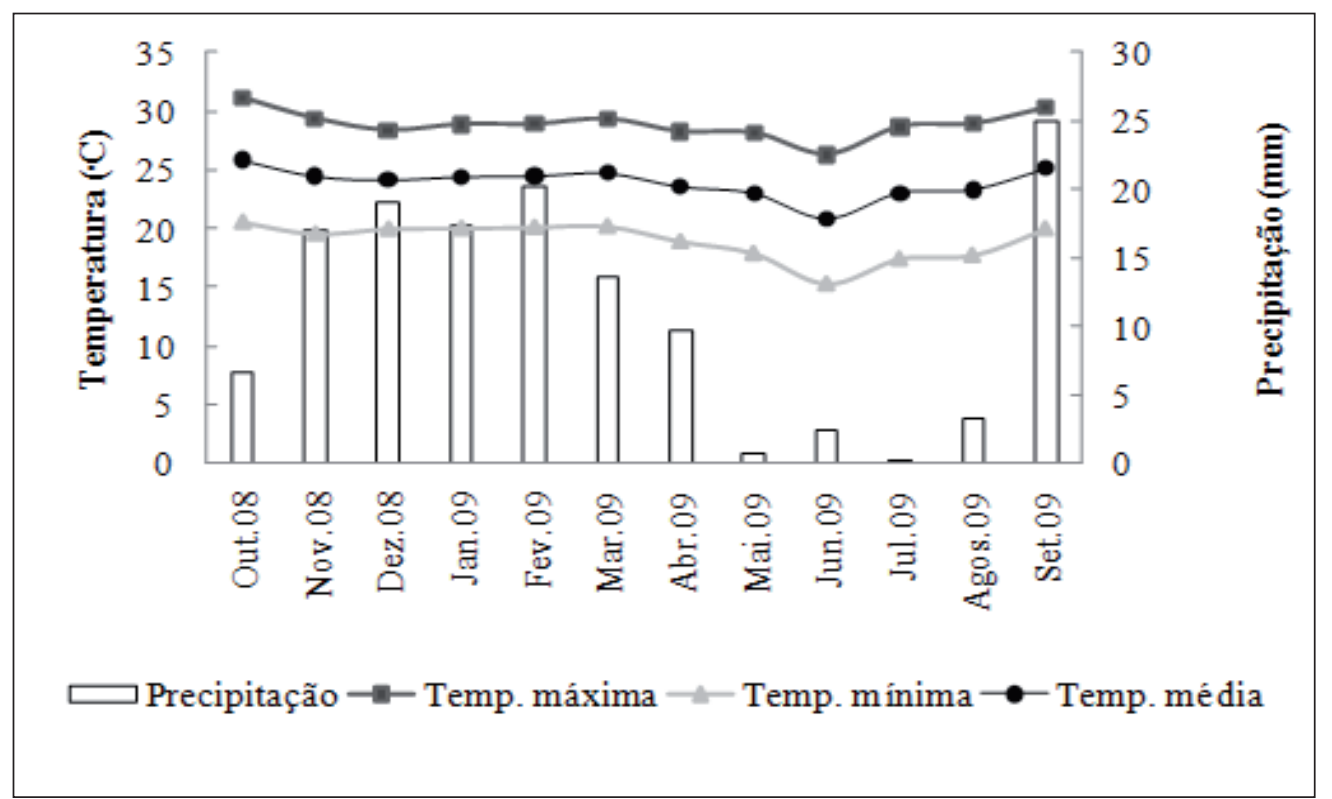

Fonte: Elaboração dos autores.

As coletas de amostras de solo foram realizadas em março (período chuvoso) e setembro (período de estiagem) de 2009, em um Latossolo Vermelho, na profundidade de 0 a $10 \mathrm{~cm}$, para realização das análises de atividade enzimática microbiana total, $\beta$-glicosidase e fosfatase ácida.
A área de cana-de-açúcar em sistema de produção orgânico sem revolvimento do solo (C) encontrava-se há nove anos sob tal condição, sendo feita a colheita mecanizada sem queima. O sistema de produção orgânico com revolvimento do solo (CO) caracterizava-se por ser conduzido assim há 
nove anos, porém com renovação do canavial e preparo de solo no quinto ano após a colheita. No período de estiagem, a colheita foi realizada de forma manual e sem queima da palha (cultura com quatro anos). A área de produção na qual o manejo orgânico se encontrava em sistema de certificação ou transição (CT), estava sendo conduzida há três anos com colheita mecanizada sem queima (cultura com três anos).

Os sistemas de produção orgânica foram tratados pela usina com $40 \mathrm{Mg} \mathrm{ha}^{-1}$ de torta de filtro, cinzas de caldeira, compostagem, aplicação de fosfatos naturais e aplicação de $180 \mathrm{~m}^{3} \mathrm{ha}^{-1}$ de vinhaça. As doses aplicadas de cada material em cada sistema de produção diferiram de acordo com a interpretação dos resultados das análises de fertilidade do solo. O manejo fitossanitário para controle de pragas e doenças foi realizado conforme a permissão da lei 10.831 de dezembro de 2003 e decreto federal 6.323, de dezembro de 2007, regulamentada para cultivos orgânicos.

Os sistemas de produção convencional se diferenciam quanto a colheita. Nas áreas onde a colheita é realizada com queima da palha (CQ) as plantas apresentavam idade de quatro anos e nas áreas nas quais não se realiza a queima da palha associada a colheita mecanizada (CC) as plantas apresentavam idade de cinco anos. As áreas de produção sob cultivo convencional foram caracterizadas pela renovação do canavial após o quinto ano de cultivo, pela aplicação de defensivos agrícolas, fertilizantes químicos na quantidade de $0,35 \mathrm{Mg} \mathrm{ha}^{-1}$ da formulação com $4 \%$ de N, 28\% de P, 20\% de K e 0,4\% de Zn e, $110 \mathrm{~m}^{3} \mathrm{ha}^{-1}$ de vinhaça. Como área de referência de sistemas naturais foi utilizada uma área remanescente de Cerrado (M), representativa da região, a mil metros das outras áreas de estudo.

Cada sistema de produção foi dividido em quatro parcelas de um hectare, coletando-se dez amostras de terra entre as linhas de cultivo para formar uma amostra composta. No período chuvoso, as coletas foram realizadas antes da colheita da cultura e, no período de estiagem, após a colheita, com exceção da área em sistema de produção convencional sem queima, que ainda não havia sido colhida. As amostras de solo foram retiradas com auxílio do trato holandês e divididas em duas amostras, sendo uma dessas destinada às análises bioquímicas e a outra para análise química e granulométrica. As amostras destinadas às análises bioquímicas foram acondicionadas em sacos de plástico e mantidas em caixa térmica à temperatura variando entre 7 a 10 ${ }^{\circ} \mathrm{C}$ por até $36 \mathrm{~h}$. Essas amostras foram passadas em peneira com malha $4 \mathrm{~mm}$ e os resíduos orgânicos como plantas, raízes e sementes foram removidos. As amostras destinadas à análise química e granulométrica foram passadas em peneira com malha $2 \mathrm{~mm}$, sendo a determinação da fertilidade do solo realizada conforme Silva (1999). O pH das amostras foi determinado em água, a concentração de $\mathrm{P}$ extraível pelo extrator Mehlich 1, o teor de matéria orgânica total por oxidação úmida. A análise granulométrica do solo foi determinada pelo método da pipeta (SILVA, 1999).

A AET foi determinada pelo método de diacetato de fluoresceína proposto por Ghini, Mendes e Bettiol (1998) e a atividade das enzimas $\beta$-glicosidase e fosfatese ácida foram estimadas de acordo com o método proposto por Tabatabai (1994), utilizando a determinação colorimétrica do $p$-nitrofenol após incubação do solo com substrato específico de cada enzima, sendo $p$-nitrofenol- $\beta$-D-glicopiranosideo e $p$-nitrofenol-fosfato, respectivamente.

Os dados de atividade enzimática oriundos dos sistemas de produção foram submetidos à análise descritiva através da estimação da média e erro padrão. Realizou-se também a análise multivariada, onde se estimou a distância entre tratamentos utilizando-se a distância Euclidiana média. Em seguida, procedeu-se ao agrupamento utilizandose o método do vizinho mais próximo (ligação completa). 


\section{Resultados e Discussão}

A cultura da cana-de-açúcar sob o sistema de produção $\mathrm{C}$ apresentou os maiores níveis de atividade da enzima $\beta$-glicosidase nas duas épocas avaliadas (Figura 2). No período chuvoso, esse sistema foi superior em 44\%, 54\%, 77\%, 79\% e $83 \%$ em relação aos sistemas CC, M, CT, CO e CQ, respectivamente, seguindo quase que as mesmas proporcionalidades no período de estiagem (47\%, $67 \%, 76 \%, 83 \%$ e $90 \%$ ). Os maiores níveis de atividade da $\beta$-glicosidase observados no manejo $\mathrm{C}$ podem ser atribuídos à adição de material orgânico provindo das adubações orgânicas, principais fontes de nutrientes para essa área, além do grande aporte de material orgânico proveniente das sucessivas colheitas bem como da deposição e lenta decomposição da palha sobre o solo.

Figura 2. Níveis da enzima $\beta$-glicosidase em diferentes sistemas de produção (CQ: manejo convencional, com queima da palha; CC: manejo convencional, sem queima da palha; CO: manejo orgânico com revolvimento do solo; CT: manejo orgânico em sistema de transição; C: manejo orgânico sem revolvimento do solo) da cultura da cana-de-açúcar e em um remanescente de Cerrado (M) em Goiatuba, GO, Brasil.

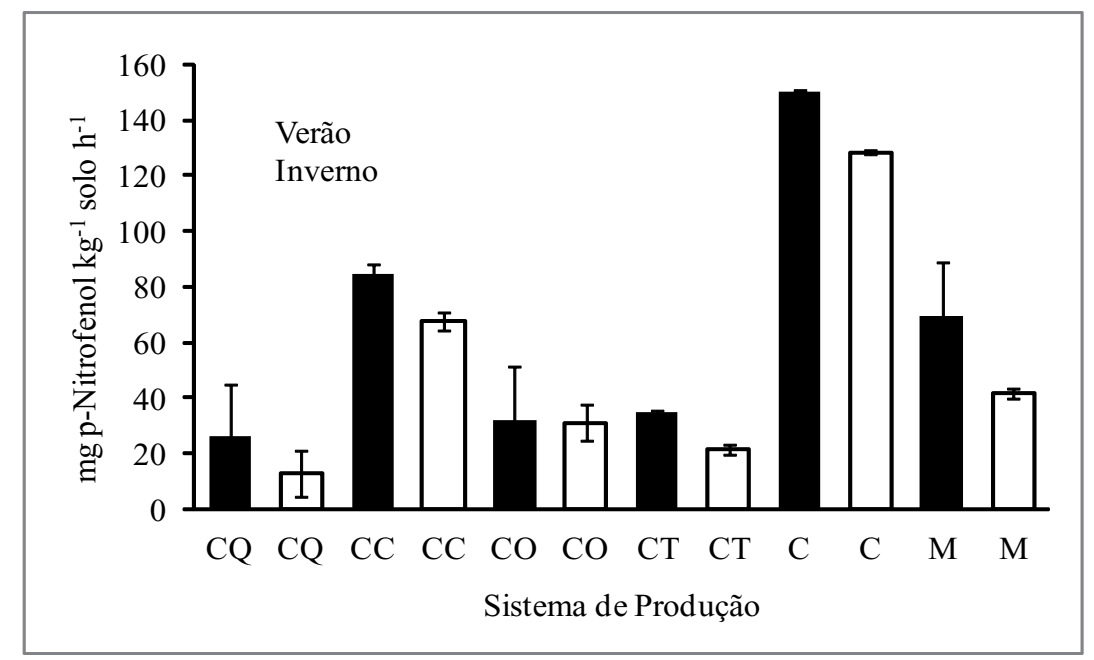

Fonte: Elaboração dos autores.

De maneira similar, Passos et al. (2008) avaliaram os níveis da enzima $\beta$-glicosidase em solos com solarização e adição de cama-de-frango e atribuíram a maior atividade desta enzima à adição de material orgânico proveniente das maiores doses. Em estudo sobre o efeito da aplicação de lodo de esgoto no solo sob os atributos biológicos de um Latossolo Vermelho do Cerrado, Souza et al. (2009) avaliaram a atividade da enzima $\beta$-glicosidase, observando que esta aumenta de acordo com o aumento da dose de lodo de esgoto aplicada, como resultado da maior quantidade de carbono contido nas maiores doses. Crecchio et al. (2001) e GarciaGil et al. (2004) também relacionaram o aumento da atividade da $\beta$-glicosidase com a adição de material orgânico provindo das doses de lodo de esgoto.

$\mathrm{O}$ manejo $\mathrm{CC}$ e a área remanescente de Cerrado (M) apresentaram o segundo e terceiro níveis mais altos de atividade da enzima $\beta$-glicosidase, respectivamente (Figura 2). O grande volume de material orgânico em decomposição no solo sob manejo $\mathrm{CC}$, já que a cultura ainda não havia sido colhida, e a adição de restos vegetais na área de Cerrado podem ter contribuído para os maiores níveis de atividade da enzima, corroborando dados apresentados por Matsuoka, Mendes e Loureiro (2003), que relataram que a atividade da $\beta$-glicosidase foi maior no sistema de cultivo perene 
de uva do que na mata e na área de soja convencional. Os autores atribuem esse fato aos restos vegetais de folhas, frutos, galhos e flores na entrelinha da videira, pois a $\beta$-glicosidase atua na etapa final da decomposição da celulose, sendo responsável pela hidrólise dos resíduos de celobiose e formando o açúcar simples $\beta$-D-glucose (TABATABAI, 1994; PAUL; CLARK, 1996).

Os menores níveis de atividade da enzima $\beta$-glicosidase foram observados na área de cana- de-açúcar com manejo $\mathrm{CQ}$, indicando que a colheita com o processo de queima promove rápida degradação da matéria orgânica do solo (MARCHIORI JÚNIOR; MELLO, 1999), não contribuindo para a atividade da enzima. Esse fato pode estar relacionado ao baixo nível de matéria orgânica (Tabela 1), fonte de carbono mantido no solo, já que a enzima $\beta$-glicosidase está ligada ao ciclo deste elemento.

Tabela 1. Valores médios de argila, silte, areia, matéria orgânica no período chuvoso (MO-V) e seco (MO-I), pH e fósforo $(\mathrm{P})$, da camada-10 $\mathrm{cm}$ de solo em lavouras de cana-de-açúcar sob diferentes sistemas de produção (CQ: manejo convencional, com queima da palha; CC: manejo convencional, sem queima da palha; CO: manejo orgânico com revolvimento do solo; CT: manejo orgânico em sistema de transição; C: manejo orgânico sem revolvimento do solo) e em remanescente de Cerrado (M).

\begin{tabular}{cccccccc}
\hline \multirow{2}{*}{ Manejo } & Argila & Silte & Areia & MO-V & MO-I & pH & P(Mehl) \\
\cline { 2 - 7 } & \multicolumn{2}{c}{$---------\mathrm{g} \mathrm{kg}^{-1}--------$} & $------0^{-}----$ & $\mathrm{CaCl}_{2}$ & $\mathrm{mg} \mathrm{dm}^{-3}$ \\
\hline CQ & 338 & 135 & 528 & 1,43 & 1,07 & 5,18 & 2,00 \\
EPM & 26,5 & 9,8 & 30,5 & 0,15 & 0,07 & 0,14 & 0,32 \\
CC & 492 & 272 & 235 & 1,83 & 1,87 & 6,05 & 2,75 \\
EPM. & 14,3 & 7,3 & 19,1 & 0,07 & 0,03 & 0,10 & 0,57 \\
CO & 468 & 262 & 270 & 1,88 & 2,27 & 5,58 & 1,43 \\
EPM & 26,5 & 23,5 & 41,5 & 0,15 & 0,14 & 0,07 & 0,91 \\
CT & 502 & 328 & 170 & 2,05 & 2,27 & 5,95 & 2,68 \\
EPM & 26,5 & 37,3 & 55,7 & 0,12 & 0,17 & 0,16 & 0,43 \\
C & 380 & 175 & 445 & 2,35 & 2,97 & 5,85 & 7,04 \\
EPM & 32,1 & 33,0 & 56,2 & 0,11 & 0,05 & 0,10 & 1,10 \\
M & 452 & 212 & 335 & 2,95 & 3,27 & 4,55 & 1,13 \\
EPM & 21,8 & 28,6 & 39,4 & 0,26 & 0,11 & 0,08 & 0,39 \\
\hline
\end{tabular}

EPM.: erro padrão da média, V: amostra coletada no período chuvoso e I: no período de estiagem.

Fonte: Elaboração dos autores.

Os maiores níveis de atividade da fosfatase ácida foram detectados na área nativa de Cerrado no período chuvoso e período de estiagem (Figura $3)$, resultados que corroboram os encontrados por Nunes et al. (2009), que encontraram níveis de atividade desta enzima maiores em áreas sem cultivo do que nas áreas cultivadas há 22 e 30 anos com café. Segundo Matsuoka, Mendes e Loureiro (2003), esses resultados podem ser atribuídos à qualidade da matéria orgânica, principal fonte de nutrientes para o crescimento das plantas. Outro fator que explica tais resultados é que geralmente áreas de mata apresentam grande quantidade de carbono orgânico, bem como fósforo orgânico contido na biomassa microbiana do solo e baixa disponibilidade de fósforo inorgânico (GATIBONI et al., 2008).

No período chuvoso, o sistema de produção C apresentou os maiores níveis de atividade da enzima fosfatase ácida entre as áreas de cultivo, sendo superior em $31 \%, 53 \%, 67 \%$ e $73 \%$ aos sistemas de produção $\mathrm{CC}, \mathrm{CO}, \mathrm{CT}$ e $\mathrm{CQ}$, respectivamente 
(Figura 3). Fator importante a ser considerado no sistema de produção $\mathrm{C}$, é a não-perturbação do solo durante o período de oito anos e, à adição de resíduos vegetais ou animais e de adubos fosfatados naturais, contribuindo para o possível acúmulo de $\mathrm{P}$ orgânico nesse sistema (CARNEIRO et al., 2004b; Partelli et al., 2009). No período de estiagem, os níveis enzimáticos decaíram para níveis menores do que os da área com cana-de-açúcar queimada (Figura 3), concordando com os resultados obtidos por Gatiboni et al. (2008).

Figura 3. Níveis da enzima fosfatase ácida em diferentes sistemas de produção (CQ: manejo convencional, com queima da palha; CC: manejo convencional, sem queima da palha; CO: manejo orgânico com revolvimento do solo; CT: manejo orgânico em sistema de transição; C: manejo orgânico sem revolvimento do solo) da cultura da cana-deaçúcar e em um remanescente de Cerrado.(M) Goiatuba, GO, Brasil.

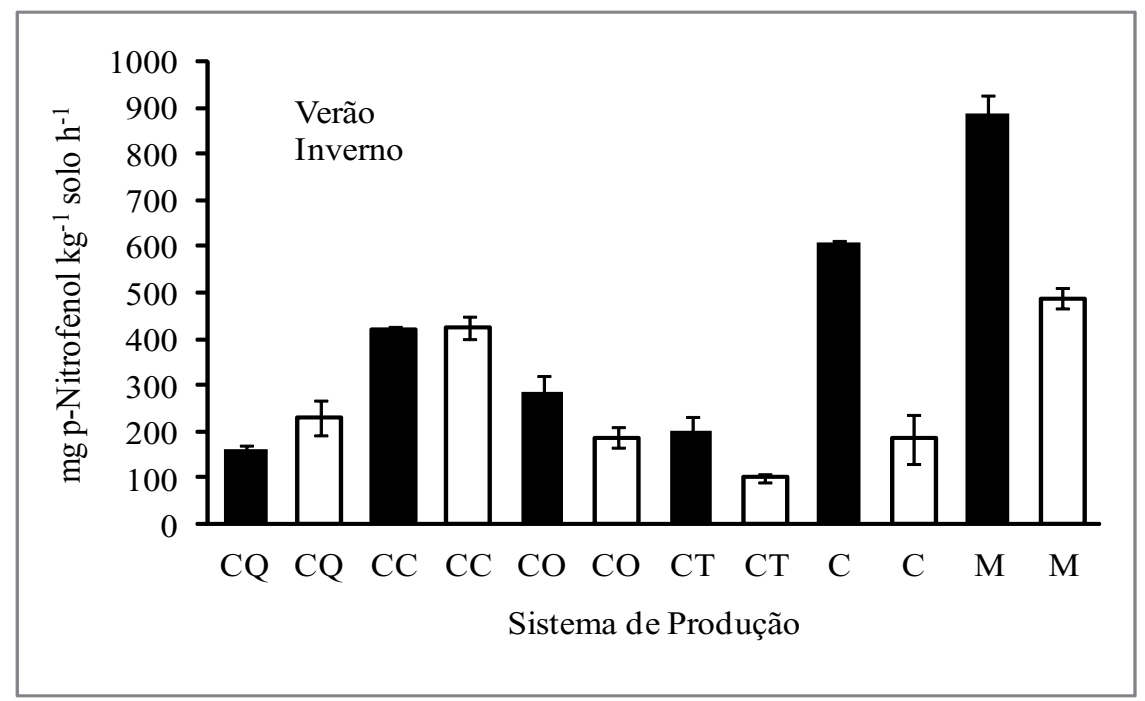

Fonte: Elaboração dos autores.

No período de estiagem, os sistemas de produção convencionais com e sem auxílio da queima se destacaram, sendo superiores aos demais. No sistema de produção convencional sem queima a atividade da fosfatase ácida foi superior em $45 \%$, $55 \%, 56 \%$ e $76 \%$ aos sistemas CQ, CO, C e CT, respectivamente (Figura 3).

Os sistemas de produção CQ e CT apresentaram os menores níveis de atividade da enzima fosfatase ácida no período chuvoso. Esses resultados podem ser atribuídos à queima da palha e à transição do sistema convencional para o orgânico. Resultados semelhantes foram reportados por Pupin (2008), onde os valores de atividade da fosfatase ácida diminuíram com o manejo de queima na colheita da cana-de-açúcar, seguido de aumento nos cortes posteriores que não se utilizaram desse sistema, concluindo que a queima influencia negativamente a atividade desta enzima.

O sistema de produção CC apresentou o maior nível de atividade da enzima fosfatase ácida quando comparado aos demais no período de estiagem, contradizendo os resultados observados por Gatiboni et al. (2008) e Raghothama e Karthikeyan (2005), que afirmam que quanto maior a disponibilidade de $\mathrm{P}$ solúvel no solo, menor é a atividade da enzima fosfatase ácida. Segundo os autores, a enzima fosfatase ácida é liberada pelas plantas e microrganismos quando há baixa disponibilidade de P solúvel no solo.

As diferenças entre os sistemas de produção convencionais e orgânicos aparentemente estão 
ligadas ao material orgânico e pela diferença de fonte de fósforo em cada sistema. Possivelmente, práticas como utilização de herbicidas não se mostraram fator decisivo na influência dos resultados como observados por Tironi (2009), onde a aplicação de herbicidas na cultura da cana-de-açúcar não influenciou na atividade de fosfatase ácida.
A atividade enzimática total (AET) é utilizada como indicador geral da atividade hidrolítica do solo, medida pelas atividades de proteases, lípases e esterases, que são capazes de clivar compostos fluorogênicos (TAYLOR et al., 2002). A atividade enzimática total na área remanescente de Cerrado foi superior à encontrada nos sistemas de produção cultivados, tanto no período chuvoso quanto no de estiagem (Figura 4).

Figura 4. Níveis de atividade enzimática total (FDA) em diferentes sistemas de produção (CQ: manejo convencional, com queima da palha; $\mathrm{CC}$ : manejo convencional, sem queima da palha; CO: manejo orgânico com revolvimento do solo; CT: manejo orgânico em sistema de transição; C: manejo orgânico sem revolvimento do solo) da cultura da canade-açúcar e em um remanescente de Cerrado. (M) Goiatuba, GO, Brasil.

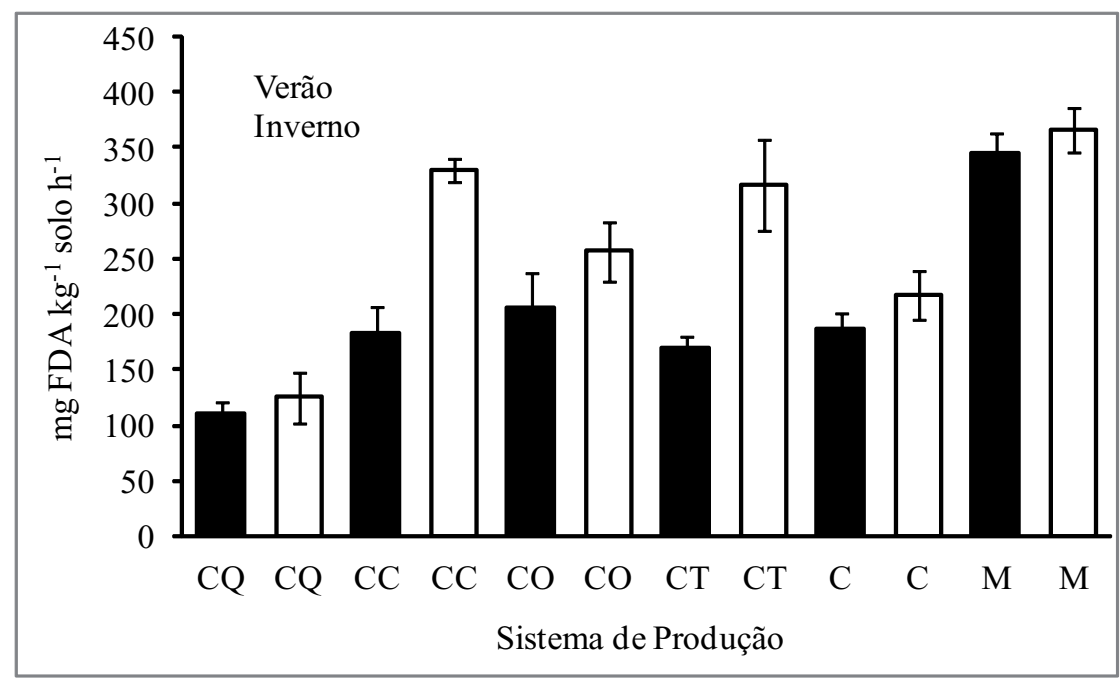

Fonte: Elaboração dos autores.

No período chuvoso, a AET em área remanescente de Cerrado foi superior em $41 \%$ ao $\mathrm{CO}$, considerado o melhor entre todos os sistemas de produção avaliados (Figura 4). Altos níveis de AET em mata foram também observados por Silva, Siqueira e Costa (2004), Partelli et al. (2012) e Sant'Anna et al. (2009), que atribuíram tais resultados à grande quantidade de matéria orgânica sob a superfície do solo.

$\mathrm{Na}$ análise por agrupamento de vizinho mais próximo (Figura 5), observou-se a formação de três grupos distintos. O primeiro agrupa os sistemas de produção CQ (período chuvoso e período de estiagem), CT (período chuvoso e período de estiagem), $\mathrm{CO}$ (período chuvoso e período de estiagem) e $\mathrm{C}$ (período de estiagem); o segundo agrupa os sistemas $\mathrm{CC}$ (período chuvoso e período de estiagem), C (período chuvoso) e M (período de estiagem); o terceiro agrupa M (período chuvoso).

Nota-se que o remanescente de Cerrado no período chuvoso, não se agrupa aos sistemas de cultivo, indicando particularidade desse solo em relação às enzimas avaliadas. $\mathrm{O}$ grupo dois aproxima o sistema CC (período chuvoso e período de estiagem) ao $\mathrm{C}$ (período chuvoso) e à área de $\mathrm{M}$ (período de estiagem), indicando que esses sistemas 
mesmo sob boas condiçoes de água, luz e calor proporcionados pelo período chuvoso, aproximase as características enzimáticas do solo na área de mata no periodo de estiagem, onde apresenta baixas condiçoes de desenvolvimento miricrobiano e vegetal. Porém, Theodoro et al. (2003) não observaram diferenças significativas entre o solo da mata e o solo de lavoura de café Arábica, sob manejo orgânico e convencional.
Já o grupo um indica similaridade entre os sistemas CQ (período chuvoso e período de estiagem), CT (período chuvoso e período de estiagem), CO (período chuvoso e período de estiagem) e C (período de estiagem) distanciandose das características apresentadas pelos grupos dois e três.

Figura 5. Divergência entre os sistemas de produção (CQ: manejo convencional, com queima da palha; CC: manejo convencional, sem queima da palha; CO: manejo orgânico com revolvimento do solo; CT: manejo orgânico em sistema de transição; C: manejo orgânico sem revolvimento do solo) e remanescente de Cerrado (M), utilizando-se a distância Euclidiana média, através do método do vizinho mais próximo, com base nas atividades enzimáticas. Goiatuba, GO, Brasil.

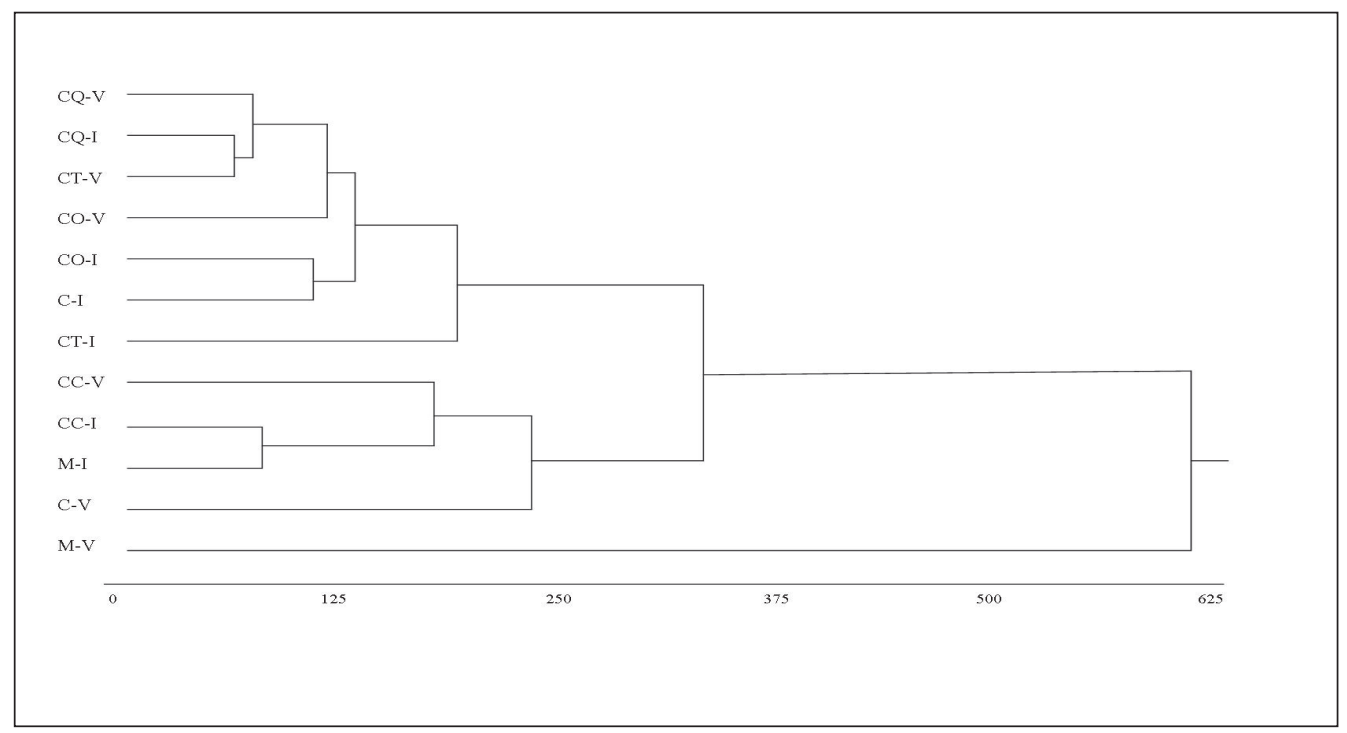

Nota: Letras antes do traço referem-se ao tipo de manejo e depois do traço à época de amostragem: V: amostras coletadas no período chuvoso; e I: amostras coletadas no período de estiagem.

Fonte: Elaboração dos autores.

\section{Conclusões}

Nenhum dos sistemas de produção avaliados apresentou características enzimáticas similares com a área remanescente do cerrado no período chuvoso, diferenciando-se na análise de agrupamento.

Os maiores níveis de atividade da enzima $\beta$-glicosidase foram observados no sistema de produção orgânico certificado de cana-de-açúcar sem revolvimento do solo, indicando maior ciclagem da matéria orgânica nesse sistema em relação aos demais.

Menor atividade enzimática total foi encontrada no sistema de produção que realiza queima da palhada antes da colheita. 
Os maiores valores de fosfatase ácida foram encontrados na área remanescente de Cerrado no período chuvoso, seguido pelo sistema de produção orgânico certificado de cana-de-açúcar sem revolvimento do solo.

\section{Agradecimentos}

À Universidade Federal de Goiás, em particular a Escola de Agronomia e Engenharia de Alimentos; À Usina Goiasa e à Embrapa Arroz e Feijão.

\section{Referências}

CARNEIRO, C. E. A.; FIORETTO, R. A.; FONSECA, I. C. B.; NEVES, C. S. V. J.; CASTRO, A. J. S. Alterações químicas no solo induzidas pela aplicação superficial de palha de cana-de-açúcar, calcário e vinhaça. Semina: Ciências Agrárias, Londrina, v. 25, n. 4, p. 265-272, 2004a.

CARNEIRO, R. G.; MENDES, I. C.; LOVATO, P. E.; CARVALHO, A. M.; VIVALDI, L. J. Indicadores biológicos associados ao ciclo do fósforo em solos de Cerrado sob plantio direto e plantio convencional. Pesquisa Agropecuária Brasileira, Brasília, v. 39, n. 7, p. 661-669, 2004b.

COMPANHIA NACIONAL DE ABASTECIMENTO - CONAB. Cana-de-açúcar: safra 2011/2012 primeiro levantamento. 2011. Disponível em: <http://www.conab. gov.br/>. Acesso em: 18 jun. 2011.

CRECCHIO, C.; CURCI, M.; MININNI, R.; RICCIUTI, P.; RUGGIERO, P. Shortterm effects of municipal solid waste compost amendments on soil carbon and nitrogen content, some enzyme activities and genetic diversity. Biology and Fertility of Soils, Heidelberg, v. 34, n. 5, p. 311-318, 2001.

DENG, S. P.; TABATABAI, M. A. Effect of tillage and residue management on enzyme avtivities in soils: III. Phosphatases and arylsulfatase. Biology and Fertility Soils, Heidelberg, v. 24, n. 2, p. 141-146, 1997.

DUARTE JÚNIOR, J. B.; COELHO, F. C.; FREITAS, S. P. Dinâmica de populações de plantas daninhas na canade-açúcar em sistema de plantio direto e convencional. Semina: Ciências Agrárias, Londrina, v. 30, n. 3, p. 595612, 2009.

FIORETTO, A.; PAPA, S.; SORRENTINO, G.; FUGGI, A. Decomposition of Cistus incanus leaf litter in a
Mediterranean maquis ecosystem: mass loss, microbial enzyme activities and nutrient changes. Soil Biology and Biochemistry, Exeter, v. 33, n. 3, p. 311-321, 2001.

GARCIA-GIL, J. C.; PLAZA, C.; SENESI, N.; BRUNETTI, G.; POLO, A. Effects of sewage sludge amendment on humic acids and microbiological properties of a semiarid Mediterranean soil. Biology and Fertility of Soils, Verlag, v. 39, n. 5, p. 320-328, 2004.

GATIBONI, L. C.; KAMINSKI, J.; RHEINHEIMER, D. S.; BRUNETTO, G. Fósforo da biomassa microbiana e atividade de fosfatases ácidas durante a diminuição do fósforo disponível no solo. Pesquisa Agropecuária Brasileira, Brasília, v. 43, n. 8, p. 1085-1091, 2008.

GHINI, R.; MENDES, M. D. L.; BETTIOL, W. Métodos de hidrólise de diacetato de fluoresceína (FDA) como indicador da atividade microbiana no solo e supressividade a Rhizoctonia solani. Summa Phytopathologica, Botucatu, v. 24, n. 3-4, p. 239-242, 1998.

JOSHI, S. R.; SHARMA, G. D.; MISHRA, R. R. Microbial enzyme activities related to litter decomposition near a highway in a sub-tropical forest of North East India. Soil Biology \& Biochemistry, Exeter, v. 25, n. 12, p. 17631770, 1993.

MARCHIORI JÚNIOR, M.; MELO, W. J. Carbono, carbono da biomassa microbiana e atividade enzimática em um solo sob mata natural, pastagem e cultura do algodoeiro. Revista Brasileira de Ciência do Solo, Campinas, v. 23, n. 2, p. 257-263, 1999.

MATSUOKA, M. Atributos biológicos de solo cultivados com videira na região da Serra Gaúcha. 2006. Tese (Doutorado em Ciência do Solo) - Universidade Federal do Rio Grande do Sul, Porto Alegre.

MATSUOKA, M.; MENDES, I. C.; LOUREIRO, M. F. Biomassa microbiana e atividade enzimática em solos sob vegetação nativa e sistemas agrícolas anuais e perenes na Região de Primavera do Leste. Revista Brasileira de Ciência do Solo, Campinas, v. 27, n. 3, p. 425-433, 2003.

NUNES, L. A. P. L.; DIAS, L. E.; BARROS, I. J. N. F.; KASUYA, M. C. M.; CORREIA, E. F. Impacto do monocultivo de café sobre os indicadores biológicos do solo na zona da área remanescente de Cerrado mineira. Ciência Rural, Santa Maria, v. 39, n. 9, p. 2467-2474, 2009.

PARTELLI, F. L.; BUSATO, J. G.; VIEIRA, H. D.; VIANA, A. P.; CANELLAS, L. P. Qualidade da matéria orgânica e distribuição do fósforo no solo de lavouras orgânicas de café Conilon. Ciência Rural, Santa Maria, v. 39, n. 7, p. 2065-2072, 2009. 
PARTELLI, F. L.; VIEIRA, H. D.; FERREIRA, E. P. B.; VIANA, A. P.; MARTINS, M. A.; URQUIAGA, S. Chemical and microbiological soil characteristics under conventional and organic coffee production systems. Communications in soil science and plant analysis. v. 43, n. 5, p. 847-864, 2012.

PASSOS, S. R.; REIS JUNIOR, F. B. dos; RUMJANEK, N. G.; MENDES, L. de C.; BAPTISTA, M. J.; XAVIER, G. R. Atividade enzimática e perfil da comunidade bacteriana em solo submetido à solarização e biofumigação. Pesquisa Agropecuária Brasileira, Brasília, v. 43, n. 7, p. 879-885, 2008.

PAUL, E. A.; CLARK, F. E. Soil microbiology and biochemistry. San Diego, Academic Press, 1996. 340 p.

PAULA, A. M.; LAMMEL, D. R.; BARTH, G.; CARDOSO, E. J. B. N. Atividade enzimática no solo em áreas de café sob diferentes manejos. In: FERTIBIO 2006, Bonito, MS. Resumos... Bonito: SBCS, 2006. CDROM.

PUPIN, B. Propriedades microbiológicas do solo alteradas por compactação. 2008. Dissertação (Mestrado em Agronomia) - Faculdades de Ciências Agrárias e Veterinária. Universidade Estadual de São Paulo, Jaboticabal.

QUILCHANO, C.; MARANÓN, T. Dehydrogenase activity in Mediterranean forest soils. Biology and Fertility of Soils, Berlin, v. 35, n. 2, p. 102-107, 2002.

RAGHOTHAMA, K. G.; KARTHIKEYAN, A. S. Phosphate acquisition. Plant and Soil, The Hague, v. 274, n. 1, p. 37-49, 2005.

RIPOLI, M. L. C.; RIPOLI, T. C. C. Palhiço como fonte de energia. In: DINARDO-MIRANDA, L. L.; VASCONCELOS, A. C. M.; LANDELL, M. G. A. Canade-açúcar. Campinas: Instituto Agronômico, 2008. p. 791-806.

SANT'ANNA, S. A. C.; FERNANDES, M. F.; IVO, W. M. P. M.; COSTA, J. L. S. Evaluation of soil quality indicators in sugarcane management in sandy loam soil. Pedosphere, v. 19, n. 3, p. 312-322, 2009.

SILVA, F. C. da (Org.). Manual de análises químicas de solos, plantas e fertilizantes. Brasília: EMBRAPA, 1999. $370 \mathrm{p}$.
SILVA, M.; SIQUEIRA, E. R.; COSTA, L. J. da. Hidrólise de diacetato de fluoresceína como bioindicador da atividade microbiológica de um solo submetido a reflorestamento. Ciência Rural, Santa Maria, v. 34, n. 5, 2004.

SILVEIRA, O. A. de. Atividades enzimáticas como indicadores biológicos de solos agrícolas do Rio Grande do Sul. 2007. Dissertação (Mestrado em Ciência do Solo) - Faculdade de Agronomia. Universidade Federal do Rio Grande do Sul, Porto Alegre.

SOARES, R. A. B.; GARCIA, J. C.; ZANATTA, G. S. C. C.; BRITO, M. C. Produção da cana orgânica. In: DINARDO-MIRANDA, L. L.; VASCONCELOS, A. C. M.; LANDELL, M. G. A. Cana-de-açúcar. Campinas: Instituto Agronômico, 2008. p. 763-790.

SOUZA, C. A.; JUNIOR, F. B. dos R.; MENDES, I. de C.; LEMAINSKI, J.; SILVA, J. E. da. Lodo de esgoto em atributos biológicos do solo e na nodulação e produção de soja. Pesquisa Agropecuária Brasileira, Brasília, v. 44, n. 10, p. 1319-1327, 2009.

TABATABAI, M. A. Soil enzymes. In: WEAVER, R. W.; ANGLE, S.; BOTTOMLEY, P.; BEZDICEK, D.; SMITH, S.; TABATABAI, A.; WOLLUM, A. Methods of soil analysis: microbiological and biochemical properties. Madison: Soil Science Society of America, 1994. p. 775-833.

TAYLOR, J. P.; WILSON, B.; MILLS, M. S.; BURNS, R. G. Comparison of microbial numbers and enzymatic activities in surface soils and sub soils using various techniques. Soil Biology and Biochemistry, Berlin, v. 34, n. 3, p. 387-401, 2002.

THEODORO, V. C. de A.; ALVARENGA, M. I. N.; GUIMARÃES, R. J.; MOURÃO JÚNIOR, M. Carbono da biomassa microbiana e micorriza em solos sob mata nativa e agroecossistemas cafeeiros. Acta Scientiarum Agronomy, Maringá, v. 25, n. 1, p. 147-153, 2003.

TIRONI, S. P. Impacto de herbicidas na atividade microbiana em solo cultivado com cana-de-açúcar. 2009. Dissertação (Mestrado em Fitotecnia) - Faculdade de Agronomia. Universidade Federal de Viçosa, Viçosa, MG. 
